\title{
ALÉM DO VISÍVEL: USO DE TECNOLOGIA RTI NOS OBJETOS DE METAL DA PENÍNSULA ITÁLICA - ACERVO DE MEDITERRÂNEO MAE-USP
}

\author{
Juliana Figueira da Hora ${ }^{1}$ \\ Recebido em: 20/11/2021 \\ Aprovado em: 30/12/2021
}

Resumo: Neste artigo nos propomos a apresentar os resultados preliminares da pesquisa de pós-doutorado em andamento no MAE-USP. O objetivo da proposta é contextualizar criticamente os objetos de metal (adornos e ornamentos) em bronze e ferro do acervo do Museu de Arqueologia e Etnologia da USP, adquiridos por intermédio de permuta ocorrida em 1964 entre o então Museu de Arte e Arqueologia da USP e museus italianos. Faz parte da pesquisa o uso de tecnologias digitais aplicadas ao material, principalmente a técnica Reflectance Transformation Imaging (RTI), com a qual pudemos oferecer um instrumental eficaz para análise das peças. Este material é proveniente da região centro-meridional da Península Itálica, com datações da Idade do Ferro, do período orientalizante e do período clássico. Intentamos dinamizar os acervos de Mediterrâneo do MAE-USP, por meio do aprofundamento das questões relacionadas à Arqueologia das sociedades proto-históricas e históricas da Península Itálica, da revisão bibliográfica, por intermédio de comparandas e de novas pesquisas arqueológicas. Com este estudo buscamos compreender melhor aspectos sócio-políticos comuns, o trânsito entre culturas e aspectos ligados às práticas de enterramento. Esta pesquisa propõe abarcar o sentido primeiro de um Museu Universitário: Pesquisa, Ensino e Extensão. Assim, buscamos reverberar o conhecimento produzido acerca deste material aos pesquisadores da área, ao público em geral e à instituição museológica. Nossa pesquisa tenciona resgatar um histórico documental do percurso das peças, seu acondicionamento no espaço deste Museu, suas problemáticas e histórico de pesquisa. Organizaremos as informações em fichas catalogadas em um banco de dados que viabilizará o acesso a um acervo organizado, com informações completas e fotos em alta resolução.

Palavras-chave: Metais; Acervo; Península Itálica; Novas Tecnologias; RTI

\section{MÁS ALLÁ DE LO VISIBLE: USO DE TECNOLOGÍA RTI EN OBJETOS METÁLICOS DE LA PENÍNSULA ITALIANA - COLECCIÓN MEDITERRÁNEA MAE-USP}

Resumen: En este artículo nos proponemos presentar los resultados preliminares de la investigación postdoctoral en curso en el MAE-USP. El propósito de la propuesta es contextualizar críticamente los objetos metálicos (adornos y ornamentos) en bronce y hierro de la colección del Museo de Arqueología y Etnología de la USP, adquiridos a través de un

\footnotetext{
${ }^{1}$ Doutora em Arqueologia - Museu de Arqueologia e Etnologia (MAE/USP); Professora Doutora da Universidade Santo Amaro (UNISA) e Professora Colaboradora da Graduação do MAE/USP Universidade de São Paulo; Pesquisadora do Labeca (Laboratório de Estudos Sobre a Cidade Antiga). E-mail: juliusp10@gmail.com. Orcid: https://orcid.org/0000-0003-2697-9248.
} 
intercambio que tuvo lugar en 1964 entre el entonces Museo de Arte y Arqueología en USP y museos italianos. El uso de tecnologías digitales aplicadas al material forma parte de la investigación, principalmente la técnica de Reflectance Transformation Imaging (RTI), con la que pudimos ofrecer un instrumento eficaz para el análisis de las piezas. Este material proviene de la región centro-sur de la península italiana, que data de la Edad del Hierro, el período orientalizante y el período clásico. Pretendemos dinamizar las colecciones mediterráneas del MAE-USP, profundizando temas relacionados con la Arqueología de las sociedades protohistóricas e históricas de la Península Italiana, revisión bibliográfica, a través de comparaciones y nuevas investigaciones arqueológicas. Con este estudio buscamos comprender mejor los aspectos sociopolíticos comunes, el movimiento entre culturas y aspectos relacionados con las prácticas funerarias. Esta investigación se propone abarcar el significado principal de Museo Universitario: Investigación, Docencia y Extensión. Así, buscamos hacer eco del conocimiento producido sobre este material a los investigadores del área, el público en general y la institución museológica. Nuestra investigación pretende rescatar una historia documental de la trayectoria de las piezas, su almacenamiento en el espacio de este Museo, sus problemas e historia de investigación. Organizaremos la información en archivos catalogados en una base de datos que permitirá el acceso a una colección organizada, con información completa y fotografías en alta resolución.

Palabras clave: Metales; Colección; Península Italiana; Nuevas Tecnologías; $R T I$

\title{
BEYOND THE VISIBLE: USE OF RTI TECHNOLOGY IN METAL OBJECTS OF THE ITALIAN PENINSULA - MAE-USP MEDITERRANEAN COLLECTION
}

\begin{abstract}
In this paper, we propose to present the preliminary results of the postdoctoral research in progress at MAE-USP. The aim of the proposal is to critically contextualize the metal objects (adorning and ornaments) in bronze and iron from the collection of the Museum of Archeology and Ethnology at USP, acquired through an exchange that took place in 1964 between the then Museum of Art and Archeology at USP and Italian museums. The use of digital technologies applied to the material is part of the research, especially the Reflectance Transformation Imaging (RTI) technique, with which we were able to offer an effective instrument for analyzing the pieces. This material comes from the central-southern region of the Italian Peninsula, dating from the Iron Age, the Orientalizing period, and the Classical period. We intend to become Mediterranean collections of MAE-USP more dynamic, by deepening issues related to the Archeology of the Italian Peninsula's proto-historical and historical societies, by reviewing the literature, through comparisons and new archaeological research. With this study, we seek to better understand common socio-political aspects, the movement between cultures, and aspects related to burial practices. This research proposes to encompass the primary meaning of a University Museum: Research, Teaching, and Extension. Thus, we seek to reverberate the knowledge produced about this material to researchers in the area, the general public, and the museum institution. Our research intends to rescue a documentary history of the pieces' trajectory, their storage in the space of this Museum, their problems, and research history. We will organize the information in files cataloged in a database that will enable access to an organized collection, with complete information and highresolution photos.
\end{abstract}

Keywords: Metals; Collections; Italian Peninsula; New Technologies; RTI 


\section{Introdução}

A coleção de Mediterrâneo e Médio Oriental do MAE-USP, nos anos iniciais de criação do Museu de Arte e Arqueologia em 1964, recebeu doações de um acervo valioso de Arqueologia Clássica e em seguida, em 1966, outras doações dos Museus de Nicosia, Chipre e de Conímbriga em Portugal, além de doações privadas, que somam este primeiro núcleo (Bezerra de Menezes, 1965b, p. 30 apud Fleming; Florenzano, 2011, p. 218). O objetivo inicial era o de promover e articular três heranças como eixo principal: a europeia, a americana e a africana. Desse modo, coleções egípcias e médio oriental, pré-colombianas, brasileiras, coleções etnográficas africanas e afro-brasileiras foram acrescentadas ao acervo (Fleming; Florenzano, 2011, p. 218).

O conjunto dos objetos de metal em bronze e ferro do acervo do Museu de Arqueologia e Etnologia da USP faz parte da coleção MMO (Mediterrâneo Médio-Oriental) doado por museus italianos, em condição de permuta, no ano de 1964. A presente pesquisa levou em conta um levantamento de 78 peças do acervo visando a pesquisa contextual e crítica desse material, cuja proveniência é identificada nas fichas catalográficas como das regiões central e meridional da Itália, mais especificamente de Marcas (Mar Adriático), Perúgia (a leste de Marcas) e das regiões da Campânia, do Lácio, da Úmbria e Sâmnio (Fig. 1), parte sul dos Apeninos, (Fig. 2) de períodos que variam entre a Idade do Ferro e o período arcaico - fase orientalizante (IX-VI a.C.), para a maioria dos objetos. Há, ainda, uma pequena parcela de artefatos de período clássico (século V a.C.). ${ }^{2}$ Esta região, na Idade do Ferro, mostra-se bastante complexa e intensa nos contatos culturais.

\footnotetext{
${ }^{2}$ Em um estudo sobre as estatuetas de bronze da Península Itálica, a Profa. Dra. Maria Isabel D’Agostino Fleming do Museu de Arqueologia e Etnologia - USP, publicou um artigo na Revista de História $\mathrm{n}^{\circ}$ 5, 1995, intitulado "Contatos culturais na Península Itálica: as estatuetas de bronze" que nos traz uma divisão cronológica dos períodos no contexto da Península Itálica, marcados por profundas modificações nas sociedades envolvidas na produção e no consumo das estatuetas de bronze desde o final da Idade do Bronze, a saber: Idade do Ferro (séculos XII-VIII a.C.); fase orientalizante e colonização grega (séculos VIII-V a.C.) (Fleming, 1995, p. 15).
} 


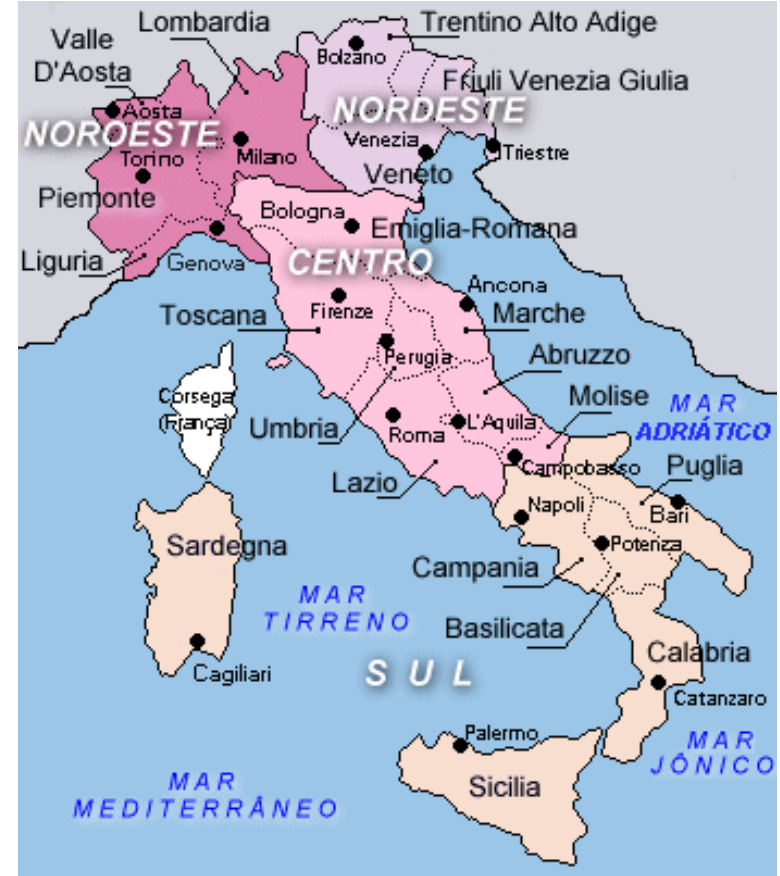

Fig. 1 - Principais regiões da Península Itálica. Fonte: M.E. Moser, The "Southern Villanovan" Culture of Campania, (Ann Arbor), 1982.

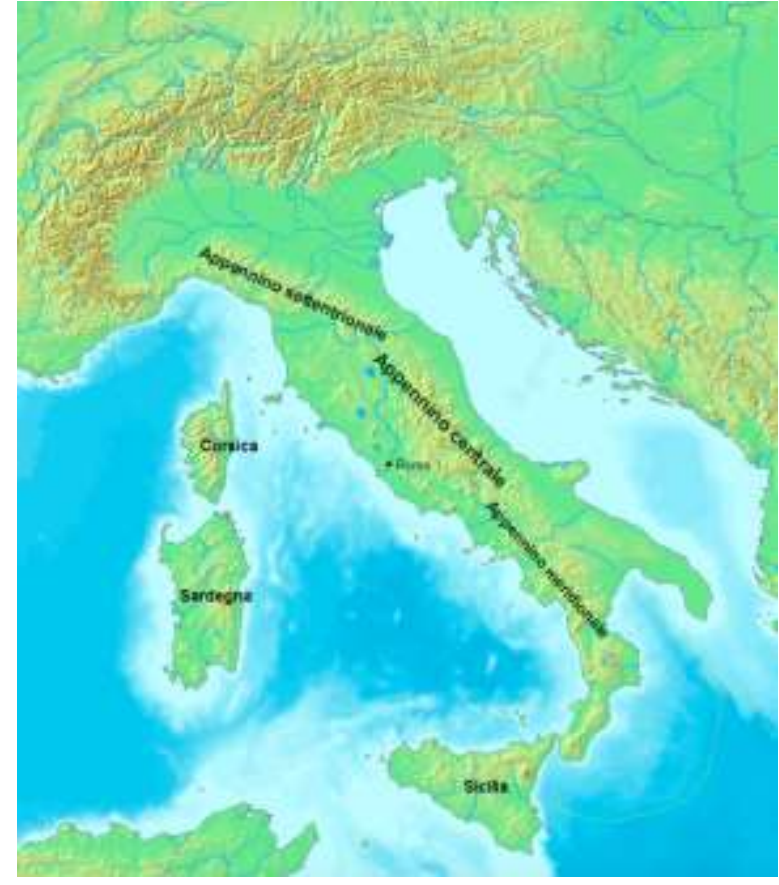

Fig. 2 - Alcance dos montes apeninos, onde se desenvolveu a cultura apenínica de norte a sul da Itália. Fonte: https://it.wikipedia.org/ wiki/Appennino_settentrionale

O MAE-USP possui um acervo de metais do Mediterrâneo bastante diverso. Na pesquisa de pós-doutorado que gerou este conteúdo, fizemos um levantamento documental dos objetos de metal das doações italianas, que contam com um número considerável de objetos em bronze. Das 78 peças mencionadas, encontram-se fíbulas de bronze, pingentes, braceletes, argolas, torques de bronze, armamentos de período arcaico e clássico, armas de ferro e maçanetas em metal não identificados (Cf. Amostra, Fig. 3). Não foram considerados, para a referida pesquisa, os vasos de bronze por não fazerem parte do nosso recorte. Estes exemplares foram doados em 25 de junho de 1964, com mais de 500 peças de diversos materiais. As peças foram enviadas da Superintendência e Museus da Itália, quando da criação do Museu de Arte e Arqueologia no Brasil. Este foi idealizado por Francisco Matarazzo Sobrinho ${ }^{3}$ durante suas viagens a Nápoles. A realização do Museu no Brasil tornou-se possível, através dos esforços das entidades oficiais italianas, das tratativas do Sr. Francisco Matarazzo e da então diretoria e reitoria da Universidade de São Paulo.

\footnotetext{
${ }^{3}$ Francisco Matarazzo Sobrinho foi um industrial ítalo-brasileiro. Foi diretor de empresas em São Paulo e um incentivador das artes plásticas. Em 1948 fundou o MAM (Museu de Arte Moderna), a Bienal Internacional de São Paulo, o Teatro Brasileiro de Comédia e o Museu de Arte e Arqueologia de São Paulo, que em 1989 constituise, a partir da fusão de museus arqueológicos e bibliográficos, como o atual Museu de Arqueologia e Etnologia da USP, dentre outros.
} 
Além do material de bronze e ferro, também vieram na permuta líticos, cerâmicas, terracotas, e outros. Tratava-se de objetos de diversos períodos e regiões da Itália, ou seja, objetos do Paleolítico, Neolítico, armas de período clássico, fíbulas de bronze e ferro, estátuas de terracota, réplicas de gesso de materiais em metal e bustos da Etrúria, da Magna Grécia e Roma.

Dentro do processo de permuta, como contrapartida, foi enviado material arqueológico amazônico: bonecas Carajá e Tapiraré, cerâmica Tucano e Caduveo, diadema, ornamento de arte plumária e armas variadas. Nas fichas catalográficas do material mediterrânico enviado ao Brasil constam doações do Museu Nacional Etrusco de Villa Giulia em Roma, Museu Nacional Pré-Histórico e Etnográfico de Luigi Pigorini de Roma e Museu Nacional de Ancona.

As peças de bronze e ferro, que foram estudadas, estão catalogadas com informações de técnica e descrição decorativa bastante lacunares, salvo algumas fichas que foram retrabalhadas por pesquisadores em anos posteriores à sua chegada no Brasil, trazendo mais informações pertinentes e contributivas na composição das fichas catalográficas. Destacamos a Profa. Dra. Maria Isabel Fleming e a Profa. Dra. Marlene Suano, e também estagiários e técnicos que inseriram dados mais detalhados nas fichas catalográficas. Deste modo, algumas fichas se encontram com uma quantidade maior de referências bibliográficas e fotos.

A maior parte do material foi documentado como de proveniência ${ }^{4}$ da Península Itálica e de regiões como Marcas na costa do Adriático (a oeste com a Úmbria, a sudoeste com o Lácio, ao sul com Abruzzo e a leste com o mar Adriático), além de bronzes de Vetulônia - a norte de Roma (datados do auge da chamada "civilização vilanoviana" do século VII a.C.), maçanetas de Pompeia e Herculano e um bracelete de Perúgia (Cf. Mapa, Fig. 1). A cronologia para este material vai de século IX a.C. ao VI a.C..

No acervo contabilizamos 24 fíbulas de bronze advindas do Museu de Villa Giulia, do Museu Pigorini e do Museu de Ancona. A proveniência foi identificada como sendo da região de Marcas no Adriático. Os pingentes de bronze contabilizam 40 objetos, dentre eles braceletes de bronze fundido doados pelo Museu Pigorini, datados do século VII-VI a.C.. Os objetos são: braceletes, pingentes, pulseiras, torques, argolas, anéis pedúnculos, pontas de lança, colares,

\footnotetext{
${ }^{4}$ Proveniência não significa contexto arqueológico em que foram encontradas. Podem ter sido remanejadas de Museus, entradas na região e não documentadas devidamente.

${ }^{5}$ Durante o final da Idade do Bronze (século XIII a.C.) e Idade do Ferro (séculos XI-VIII a.C.) a chamada "civilização apenínica", desenvolvida na Itália Meridional dominou a área e difundiu-se para norte e sul da Península Itálica. Com a unificação cultural a partir do século XII-XI a.C. ocorreu um processo de unificação dos grupos, em que os povos estiveram em constante contato, marcando uma modificação cultural. Convencionou-se chamar esta segunda fase de "civilização vilanoviana", observada na área centro-setentrional (onde mais tarde se desenvolverá a "civilização etrusca"), também na parte meridional entre a Campânia e a Lucânia, com variações locais de um tipo de cultura comum e populações diversas (Fleming, 1995, p. 16).
} 
contas de colar de bronze, datados entre os séculos IX-VI a.C.. Há 4 maçanetas de metal não identificadas, com proveniência de Pompeia/Herculano e Vetulônia, sem datação.

Fizemos o levantamento de cinco armas de bronze doadas pelo Museu Pigorini: machado, faca de bronze, disco peitoral, datados do século VIII- VII a.C. e o elmo coríntio e perneira, datados do período clássico, ou seja, século V a.C.. O material em ferro consiste em 4 armas datadas do século VI-VII a.C., permuta do Museu de Ancona, provenientes de Marcas na Itália. Trata-se de um conjunto que envolve esfera de ferro achatada, extremidade oval de utensílio de ferro, ponta de lança de ferro e machado de ferro.

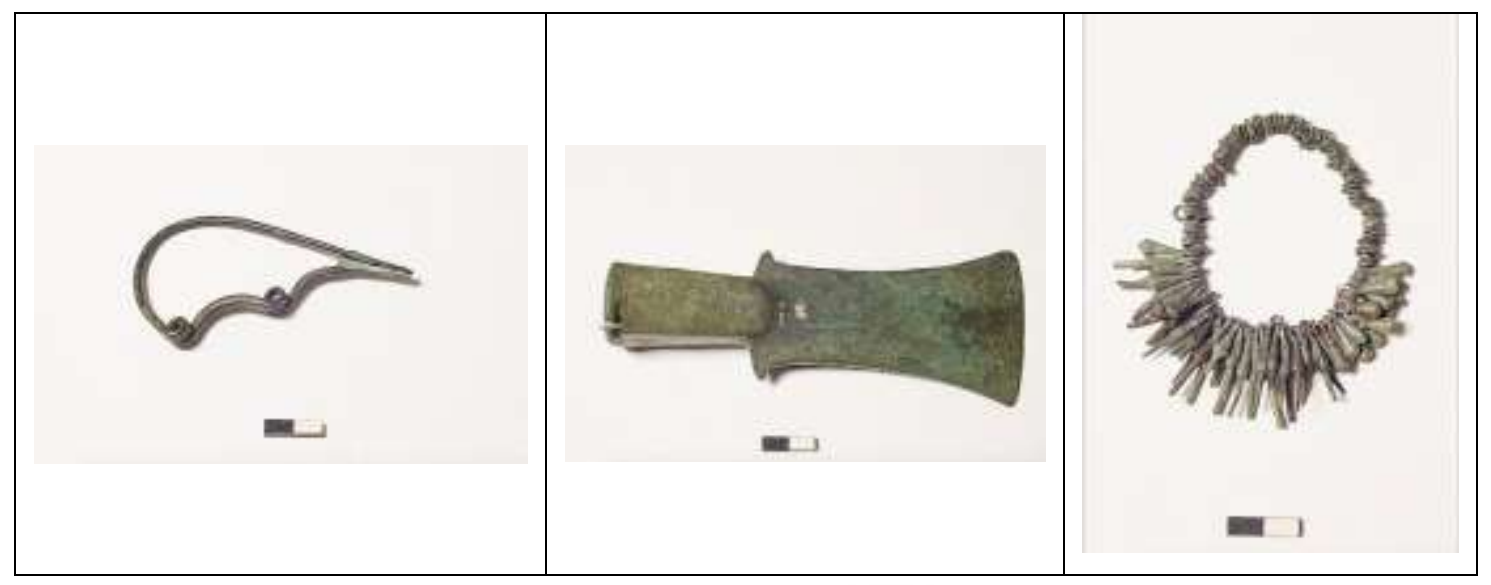

Fig. 3 - Amostra de três dos 78 objetos do acervo MMO- metais MAE-USP (da esquerda para a direita fíbula, machado e colar de bronze). Fotografias: Ader Gotardo- MAE-USP.

De acordo com Maria Isabel D’Agostino Fleming, professora da área de Mediterrâneo do Museu de Arqueologia e Etnologia-USP, em comunicação apresentada no XVI Congresso Nacional de Estudos Clássicos (Fleming, 2007, p. 51) o metal no Mediterrâneo arcaico foi essencial no desenvolvimento das aristocracias que surgiram no decorrer do século VIII - VI a.C., especialmente ferro, estanho e cobre, metais essenciais para a fabricação de armas. Além da circulação intensa de metais entre Oriente e Ocidente para o controle e produção de itens ligados às armas, o mundo aristocrático caracterizou-se pela troca de presentes, objetos de prestígio, incluindo joias, armas, vasilhas de banquete de metal, acompanhando, segundo Fleming, o desenvolvimento tecnológico da metalurgia (Ibidem).

De acordo com Holloway (1994), a Idade do Bronze italiana destacou-se na exploração de seus recursos naturais, especialmente no desenvolvimento da mineração de cobre na Sardenha. Os fenícios poderiam já estar envolvidos neste comércio. Uma parte do continente testemunhou um desenvolvimento precoce no crescimento de grandes assentamentos no Vale do Pó, onde os chamados Montes Terremare trazem vestígios de cidades bem organizadas que 
começam a despontar no final do segundo milênio (Holloway, 1994, p. 14). A chamada cultura dos Apeninos, povos que viviam em assentamentos dispersos e que se reuniam de tempos em tempos em santuários geralmente associados a nascentes e cavernas, desenvolveu-se principalmente na Itália Meridional, difundindo-se do sul para o norte (Fleming, 1995, p. 15).

A partir do século XII-XI a.C. houve uma primeira fase do fenômeno distintivo de unificação cultural, o chamado "sub-apenínico". Em uma segunda fase (séculos XI-VI a.C.), já bastante imersa no período orientalizante, convencionou-se chamar de "civilização vilanoviana". A primeira área observada foi a centro-setentrional (área de posterior desenvolvimento da civilização etrusca). Houve um maior florescimento na Itália Meridional entre a Campânia e a Lucânia. De acordo com Bianchi Bandinelli a unificação ocorrida na Idade do Ferro não possui particularidades étnicas nem políticas (Bianchi Bandinelli, 1976, p. 24 apud Fleming, 1993, p. 4).

A cultura vilanoviana ${ }^{6}$ estendeu-se por uma parte considerável da Península Itálica, incluindo a área da Toscana, zona costeira do Lácio, parte meridional - incluindo Roma, Campânia (especialmente Cápua), a área de Salerno, territórios do Adriático, em particular Marcas. O nome deriva de um sítio de Villanova, situado na Bolonha, cuja necrópole foi inicialmente escavada por Giovanni Gozzadini em 1853. De acordo com Amílcar Guerra (2015), o alcance cultural foi amplo e seu desenvolvimento inicia-se na Idade do Ferro (século IX a.C.) e apresenta-se como um perpetuador da cultura proto-vilanoviana. Esta última associada às práticas funerárias de incineração e pelo depósito de restos de urnas com decoração característica associada a objetos de metal de bronze sofisticados. A cultura material vilanoviana caracteriza-se pela prática funerária de incineração, ainda em período de transição da proto-vilanoviana para a vilanoviana, perdurando até o final da Idade do Ferro. As urnas funerárias foram depositadas em fossas, cobertas e invertidas e os objetos foram depositados junto aos ossos. Nestes enterramentos encontrou-se objetos como fíbulas em bronze, em especial em arco serpenteado (Fig. 4) e diversos adornos associados.

\footnotetext{
${ }^{6}$ Cf. Nota 4.
} 


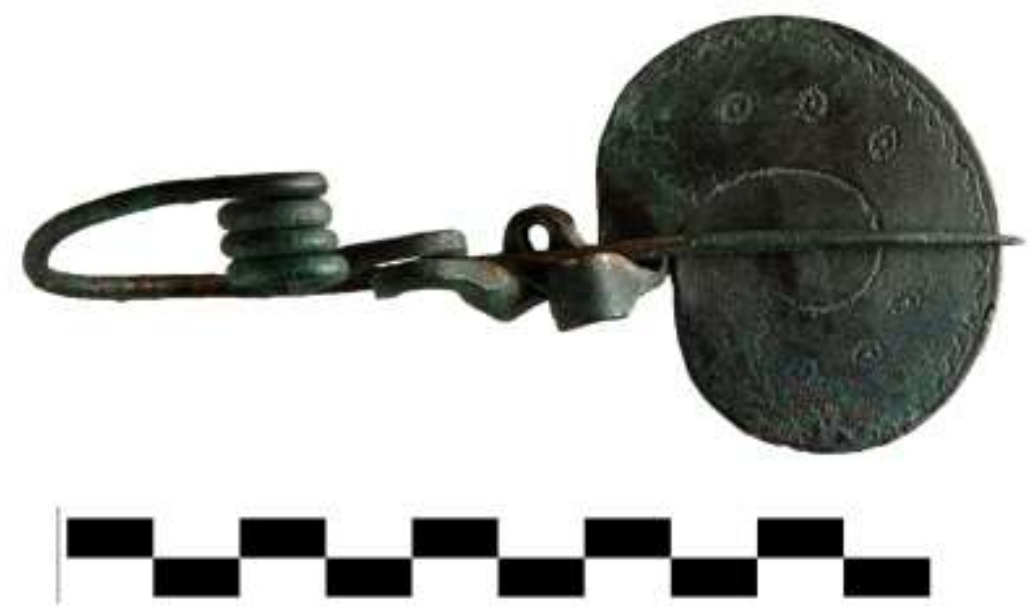

Fig. 4 - Fíbula de arco serpentiforme da coleção MMO-MAE-USP. Foto acervo MAE-USP. Fotografia Guilherme Rodrigues, 2020. Imagem após tratamento.

Progressivamente, no final do século VIII a.C., na chamada fase orientalizante, as práticas funerárias mudam e começam a abundar as inumações com uma quantidade ainda importante de objetos de bronze (Guerra, 2015, p. 14-15).

Contextos de enterramento na Idade do Ferro e no período orientalizante na região meridional e central da Itália

Na Idade do Bronze e Idade do Ferro, de acordo com os registros arqueológicos da Península Itálica, os mortos eram, em sua maior parte, cremados. Juntamente com as cinzas eram depositados broches (fíbulas) e também ornamentos junto a tigelas de argila. As urnas eram depositadas em poços quadrados encaixados com pedras ou poços. Alguns itens eram escolhidos de acordo com o sexo dos mortos, como broches, armas e/ou navalhas de bronze, ferramentas de tecelagem e fiação, como fusos e pesos de armação, ou frascos de âmbar de vidro e joias.

$\mathrm{Na}$ fase orientalizante, no final do século VIII a.C., ocorre uma mudança nos padrões de enterramento, começando a aparecer as inumações. As mulheres apresentavam ornamentos de broches, colares e pingentes, que se distribuíam, sobretudo, no busto e nas laterais do corpo (Romito, 2006, p. 49). As mudanças de padrão nos enterramentos mostram a transformação 
advinda dos diálogos entre os povos, como podemos observar cronologicamente nesta região. De acordo com Van Dommelen (2011), dependendo da natureza e da intensidade dos encontros, as pessoas vão procurar formas, tanto físicas como conceituais, para compreender o novo, adotando novas práticas rituais e/ou perpetuando elementos locais e adquirindo novos objetos como cultura material (VAN DOMMELEN, 2006; VOSKOS AND KNAPP, 2008 apud VAN DOMMELEN, 2011, p. 6).

\section{Cremações - Idade do Ferro (séculos IX - VI a.C.) - Proto-Vilanoviano/Vilanoviano}

De acordo com R. Holloway (1994), na esfera da cultura dos Apeninos, foram encontrados 1000 cemitérios de urnas de cremação que sinalizam uma importante prática na cultura da Península Itálica. Essas cremações, que também são caracterizadas por diferentes estilos de decoração de cerâmica, tipos de bronzes, como a fíbula do arco de violino, fíbulas de arco simples, facas de lados curvos e lâminas retas e curvadas, são referidas como pertencentes à chamada cultura "proto-vilanoviana" (Holloway, 1994, p.14). Esses artefatos vêm dos cemitérios de cremação da Idade do Ferro da Itália central (ver mapa, Fig. 1), próximos à Bolonha, encontrados em 1853 e datados do século IX a.C.. A cultura proto-vilanoviana, a antecessora da clássica cultura vilanoviana, é amplamente representada no Lácio (ver também mapa, Fig. 1). Estudos de caso na região da Campânia e mais ao sul, na região da Lucânia, no Apenino Meridional (ver mapa, Fig. 2). também apresentam práticas de cremação com metais depositados em urnas ornamentadas e depositadas em fossas, como por exemplo na necrópole de Sant'Antônio da Idade do Ferro, onde foram recuperadas 127 tumbas de cremações, datadas da Idade do Ferro, e de inumações, ligadas à fase orientalizante na região (Romito, 2006, p. 19).

No contexto de cremação de tumbas escavadas nas regiões dos Apeninos encontrou-se vasos de cerâmica e fíbulas de bronze associadas. Tomemos o exemplo de uma tumba da necrópole de Sant'Antonio (Cf. Fig. 5), escavada em 10 de outubro de 1959 a uma profundidade de 2,50 m. No local foram encontrados, além de um vaso de cerâmica, uma urna bicônica ${ }^{7}$ usada para fins de cremação, coberta por um vaso-tigela também em cerâmica. Estes elementos estão documentados no catálogo do Museu Provincial da Lucânia Ocidental, publicado em 2006. As fíbulas encontradas são bastante comuns em contextos de enterramentos femininos na região, associados à cultura vilanoviana do século IX a.C. (Romito, 2006, p. 47).

\footnotetext{
${ }^{7}$ Urna utilizada para incineração, possui a forma de dois cones opostos, unidos pela base. As urnas vilanoviana possuem uma ou duas alças verticais. A sua altura pode variar entre 30 e $45 \mathrm{~cm}$.
} 


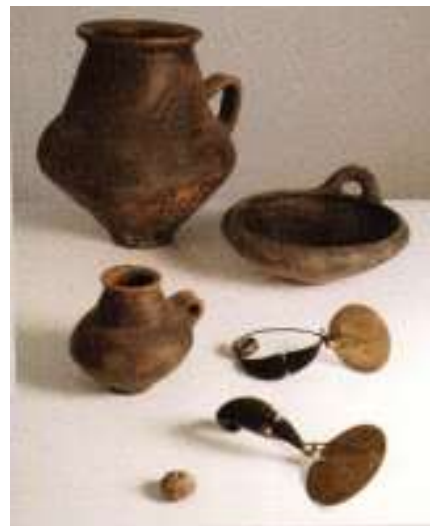

Fig. 5 - Objetos encontrados em contexto de cremação em Sant'Antonio - Província da Lucânia (duas urnas bicônicas, um vaso tigela, um pequeno objeto de cerâmica e duas fíbulas (Romito, 2006, p. 47).

Em uma tumba no contexto de cremação de um centro samnita, em Caudium, situada na região apenínica central, foi encontrado um assentamento indígena da Idade do Ferro. Juntamente ao assentamento, um complexo funerário foi revelado. Uma das tumbas, a de Montesarchio, em Caudium (Fig. 6), trouxe uma cremação com resíduos de ossos queimados, identificados como de uma mulher, envolto com ornamentos em bronze, entre fíbulas, discos e anéis (Fariello, 2007, p. 19-20).
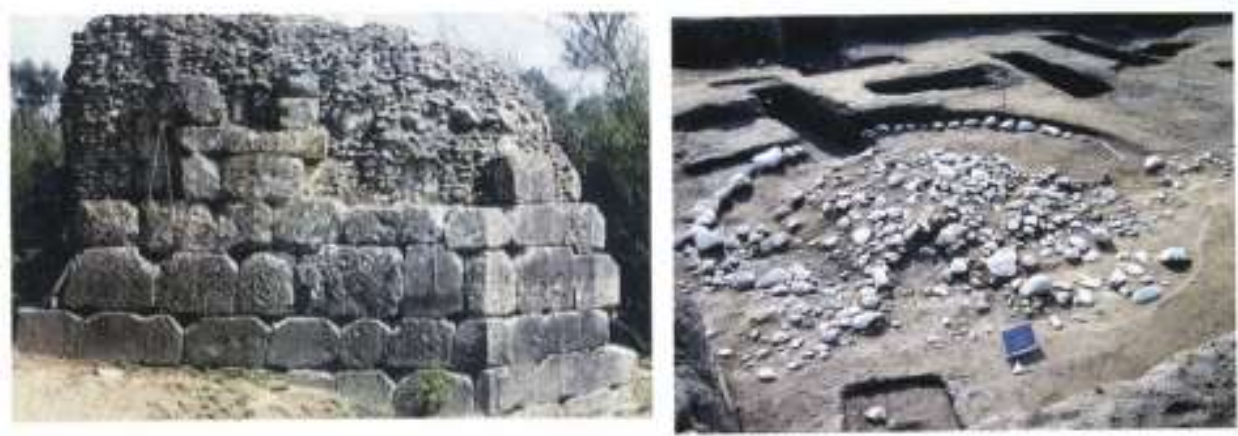

Fig. 6 - Contexto de cremação da Idade do Ferro em Montesarchio - Caudium (Fariello, 2007, p. 19).

A recuperação destes contextos específicos, registrados em diversas necrópoles do Apenino Meridional, Central e Setentrional (Cf. Mapa, Fig. 2), trazem elementos importantes como tipo de material, sexo do indivíduo, e a possibilidade de comparanda regionais, locais, observação nas mudanças e transformações sociais para os objetos de bronze provenientes das áreas comuns. 


\section{Inumação - período orientalizante na região apenínica meridional, central e setentrional da Itália (séculos VIII-VI a.C.) - Cultura Vilanoviana}

De acordo com Fleming (1993) a última fase vilanoviana confirma-se coincidentemente com a civilização orientalizante ou plenamente etrusca. Houve continuidade de elementos vilanovianos no período orientalizante (Fleming, 1993, p. 5). Do século VIII a.C. ao V a.C. observa-se um processo de articulação de culturas indígenas e gregas, com a interpenetração de fundações gregas na Itália Meridional (Piceno, Campânia) e Sicília.

No final do século VIII a.C., já na fase orientalizante, observou-se mudanças nos modos de enterramento, surgindo as inumações como padrão para grande parte da região dos Apeninos. Ainda em Sant'Antonio, na parte meridional dos Apeninos, foram escavadas tumbas do período orientalizante bastante ornamentadas com pequenos objetos de bronze (Fig. 7). Estes estão associados à cerâmica geométrica, dentre outros objetos importados da Grécia e de outros locais do Mediterrâneo (Romito, 2006, p. 52).

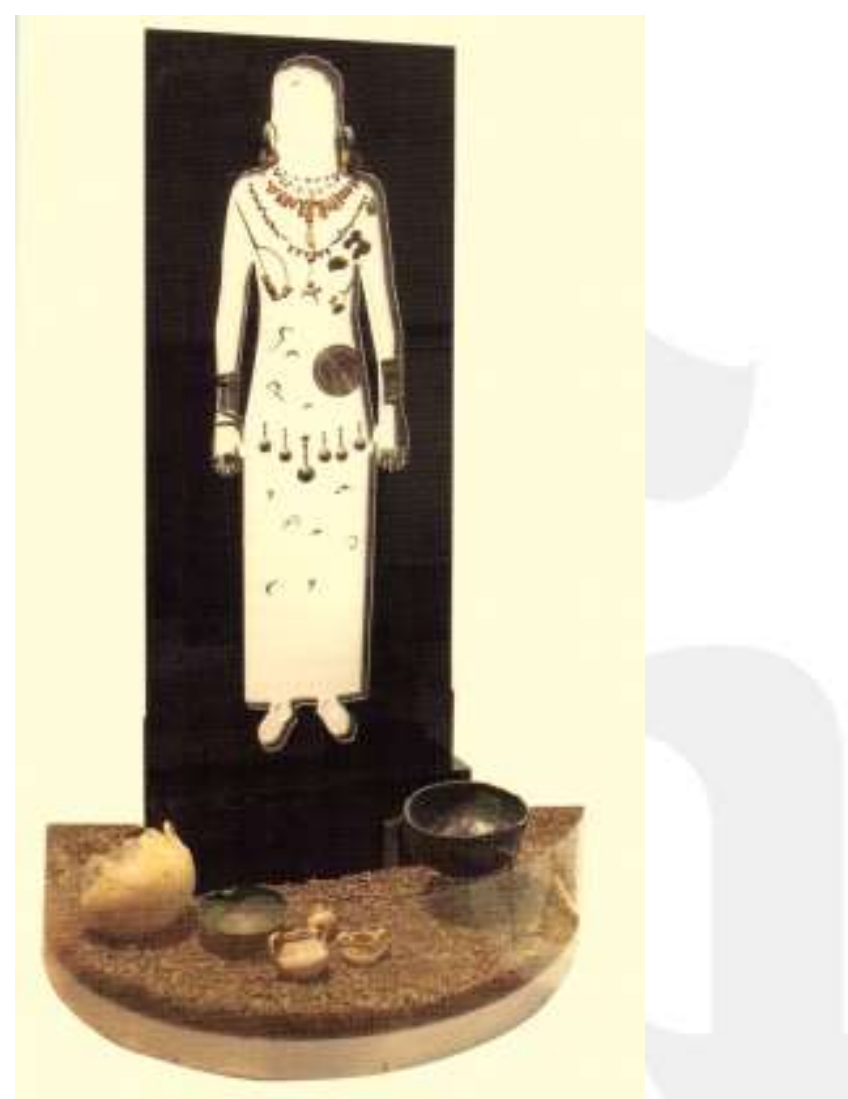

Fig. 7 - Reconstituição de enterramento em inumação e ornamentos de bronze - Período orientalizante - Sant'Antonio - Província da Lucânia (Romito, 2006, p. 51). 


\section{Impacto das fundações gregas na Península Itálica}

No século VIII a.C., o sul da Itália foi aberto às fundações gregas na região. Em um século, a maior parte da costa da Sicília e a região entre Tarento e os Estreitos de Messina haviam sido colonizadas. Mais ao norte, os comerciantes gregos haviam se estabelecido na ilha de Ischia e forneciam um canal de comércio para atender aos clientes italiotas. Através dos contatos orientais, as importações começaram a chegar à Etrúria e ao Lácio. Ross Holloway (1994, p. 14) acredita que a presença fenícia na Sardenha remonte a este período. O impacto da colonização grega e fenícia sobre o Lácio e seus vizinhos sempre foi evidente. Os etruscos, envolvendo assim o antigo Lácio, estavam destinados a ser uma força importante no desenvolvimento cultural da antiga cidade de Roma (Holloway, 1994, p. 14-17).

De acordo com Albert J. Nijboer (2010), a Itália tornou-se uma região central de contato no século IX a.C., devido à sua economia aberta, com liberdade e poucas restrições na transferência e comunicação. Essa rede de centros em ascensão também pôde acomodar vários grupos de diversos lugares, como os sardos, os povos dos Bálcãs, fenícios e eubóicos, que chegaram à Península Itálica durante a Idade do Ferro. Os diversos povos que ocuparam a região anteriormente aos gregos, como vimos, entre os séculos (XIV-XIII a.C.), travaram contatos uns com os outros e com distintos grupos culturais por meio das correntes de comércio provenientes do Egeu (Fleming, 1993, p. 1). Vale ressaltar que nenhum desses grupos tornou-se dominante. De acordo com Nijboer, a colonização grega do Sul da Itália ainda não era dominante antes do século VII a.C., pois não há evidência de controle grego em torno dos assentamentos que foram fundados (Nijboer, 2010, p. 1).

Outra característica do período é a impressionante diversidade regional que encontramos na Península Itálica desde o início da Idade do Ferro, e daí em diante, quando cada centro construiu sua cultura material selecionando, ajustando e incorporando artefatos e hábitos explícitos de seus vizinhos e de seus contatos inter-regionais ou de estrangeiros.

De acordo com Nijboer (2010), percebe-se que há várias rotas de seleção e de processos culturais que são locais e diversos. A posição da Península Itálica nos numerosos mapas de distribuição mediterrânicos e europeus também implica no estabelecimento de rotas bem marcadas, atravessando toda a península de norte a sul e de leste a oeste. Essa rede de intercâmbio intensificou-se consideravelmente a partir da segunda metade do século IX a.C. devido à crescente mobilidade, centralização, formas de urbanização precoce e crescimento da população (Nijboer, 2010, p. 3). Dentro desta rede, os centros vilanovianos se tornaram dominantes. A reconstrução do caráter dessas interconexões levanta imediatamente tópicos 
como a sincronização e a cronologia absoluta para as regiões da Península Itálica, de norte a sul (Bartoloni; Delpino, 2005). As correlações dadas nesta sessão deixam claro que qualquer alteração na cronologia absoluta da Idade do Ferro desta região trouxe importante repercussão nas áreas vizinhas. No final do século VIII a.C. houve uma mudança considerável na região, pois passa-se da fase vilanoviana para a uma fase orientalizante.

Por sua vez, o século VIII a.C. não representa apenas uma transição estilística, mas registra para a região central da Península Itálica um rearranjo da sociedade com a formação inicial do Estado, o estabelecimento da classe social, a ascensão dos princípios de formação de vários aspectos da urbanização (Nijboer, 1976, p. 4).

Considerando-se as semelhanças no registro material e funerário, percebe-se na região de Marcas, no Adriático (de onde advém a maior parte dos objetos de bronze do acervo do MAE-USP), um marcante estreitamento das relações comerciais entre a Itália Oriental e os Bálcãs. Pode-se dizer, de acordo com Nijboer (1976), que é possível reconstruir uma koiné cultural para os locais costeiros ao longo do Adriático, revelando uma estreita rede de comunicação com os Bálcãs, a partir do início da Idade do Ferro.

De acordo com Shefton (2003), é possível rastrear alguns objetos eubóicos datados do século IX a.C. no Sul da Itália. Não há registro arqueológico da presença de grupos helênicos no centro e norte do Adriático durante o século VIII a.C. e na maior parte do século VII a.C.. Apenas verificou-se o estabelecimento de centros comerciais como Spina e Adria em torno de 550-500 a.C.. Isto resultou em uma importação de um número significativo de cerâmica grega em cidades como Bolonha. Antes do final do século VI a.C., quase não havia demanda pela cerâmica grega no norte da Itália (SHEFTON, 2003).

\section{A técnica de RTI (Reflectance Transformation Imaging) e suas aplicações}

No eixo metodológico este trabalho buscou apresentar, testar hipóteses tecnológicas de aplicação e organização de um banco de dados. Para tanto, aplicou-se nos objetos do acervo MMO (Mediterrâneo Médio-Oriental), a técnica Reflectance Transformation Imaging (RTI), por meio de softwares chamados RTI viewer e RTI Builder, que nos permitem manipular as fotos de diversos ângulos e enfoques de luz, a fim de evidenciar detalhes que não são possíveis de se observar pelo uso da fotografia convencional. Aliamos estes a métodos tradicionais de registro de fotografia 2D para fins de Banco de Dados, desenhos, com o objetivo de não apenas registrar, preservar e exibir os artefatos, mas também de analisá-los e compará-los para que haja melhor compreensão das técnicas utilizada na produção dos achados arqueológicos. 


\section{Ferramentas metodológicas (materiais): organização de fichas catalogais}

Utilizamos o programa File Maker Pro para a montagem do Banco de Dados. Esta ferramenta proporcionou-nos inserção, organização e cruzamento de dados em um formato de ficha montado para atender as demandas de informações das peças. $\mathrm{O}$ banco de dados por nós montado está apto a integrar os dados no sistema Sophia, este já utilizado no MAE-USP para acervos. Criamos fichas bem estruturadas, com informações completas da pesquisa, abertura para links que possibilitam a quem acessar ter acesso a sites comparanda ${ }^{8}$, um link que direcione também às imagens obtidas através dos testes com RTI à plataforma online do MAE. A proposta surgiu da necessidade de valorização do acervo do Museu de Arqueologia e Etnologia - MAE-USP enquanto uma instituição que acondiciona material, forma pesquisadores e como local de extroversão do conhecimento.

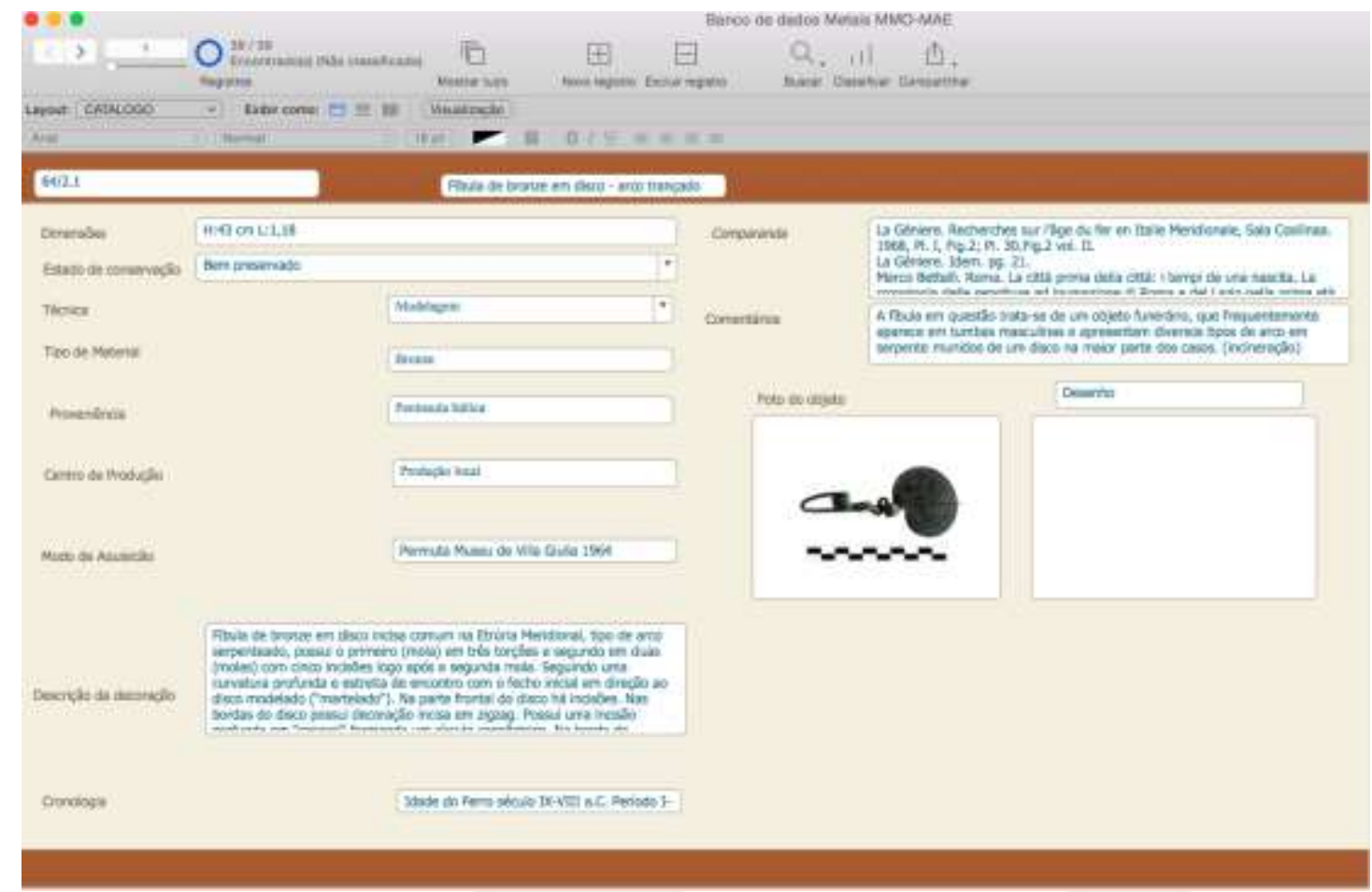

Figura 8 - Modelo de fichas em File Maker. Organização das peças em Banco de dados.

\footnotetext{
${ }^{8}$ Sites Comparanda: sites que tragam informações sobre peças semelhantes, podendo ser de Museus, links de mapas e/ou informações mais aprofundadas sobre o objeto e seu contexto.
} 


\section{Conservação e preservação de materiais: RTI Reflectance Transformation Imaging}

RTI é o mapeamento de textura polinomial, que foi desenvolvido em 2001 pela Hewlett Packard Laboratories (Malzbender et al., 2001) e é uma técnica de imagem não destrutiva, acessível e fácil de realizar. Esta técnica permite criar uma re-iluminação interativa do objeto, fazer simulações matemáticas de aprimoramento da superfície e dos atributos de cor. Existem muitas aplicações interessantes no campo do patrimônio cultural, baseadas em sua capacidade de adquirir e representar as propriedades de 3D dos objetos. Comparado ao mapeamento de textura tradicional, mapas polinomiais de textura e imagens de transformação de refletância fornecem maior definição, incluindo cores de superfície, auto-sombreamento, espalhamento de sub-superfície e inter-reflexões (Kotoula; Kyranoudi, 2013, p.76).

Trabalhos anteriores sobre Reflectance Transformation Imaging (RTI) no campo de antiguidades e obras de arte demonstraram as vantagens potenciais desta técnica em muitas áreas de pesquisa e conservação arqueológica. Um estudo realizado com moedas romanas de cobre e prata, publicado pela E-conservation Magazine 2013 (www.econservationline.com/content/view/1101) mostra os testes bem sucedidos, cujos resultados indicaram que o RTI não apenas auxilia na identificação de camadas mais profundas de detalhes de confecção e modos de produção das moedas, mas também traz contribuições importantes no campo da conservação preventiva. Do mesmo modo, fornece acesso às coleções de patrimônio cultural, por meio de imagens altamente detalhadas, como demonstra o processo de aprimoramento da imagem abaixo:

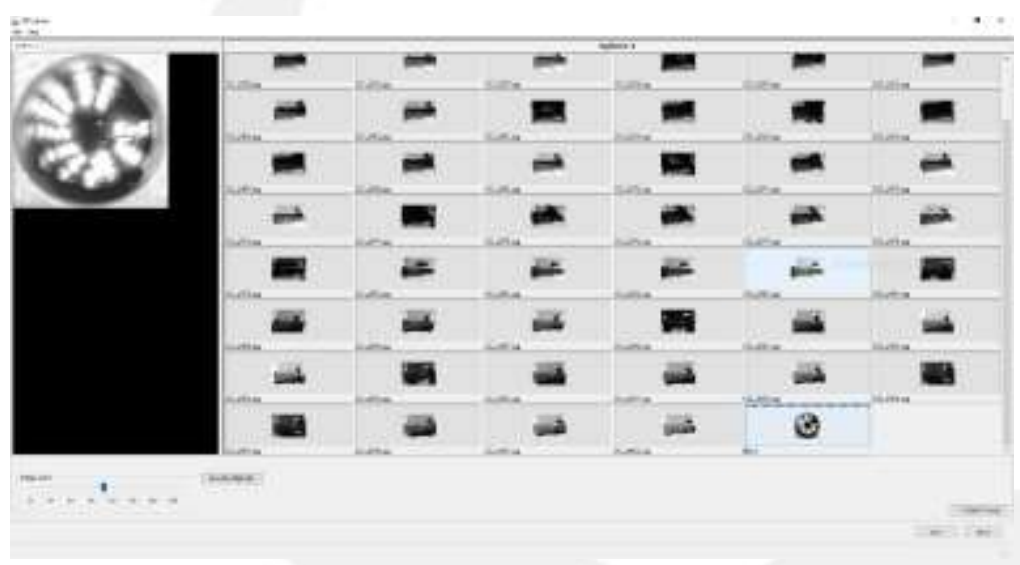

Fig.9 


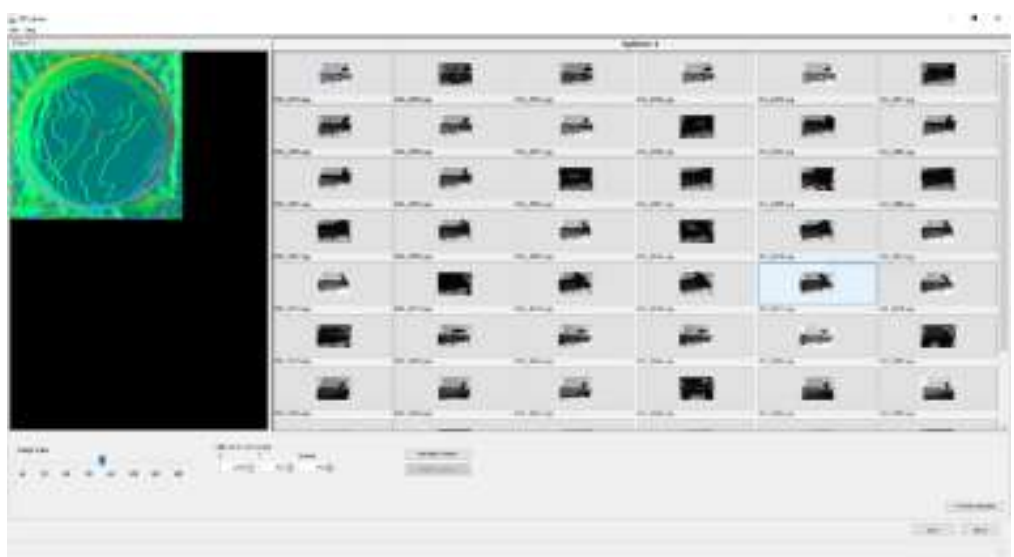

Fig.10

Figuras 9 e 10 - Programa RTI Building em processamento.

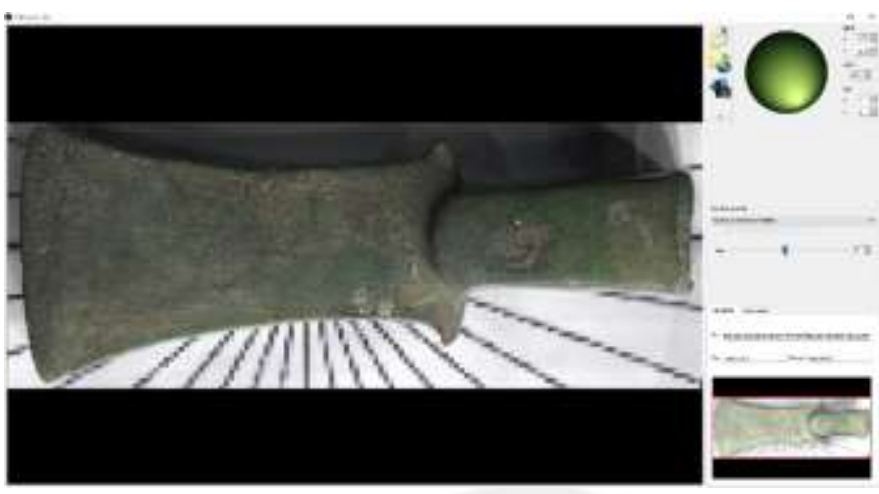

Fig.11

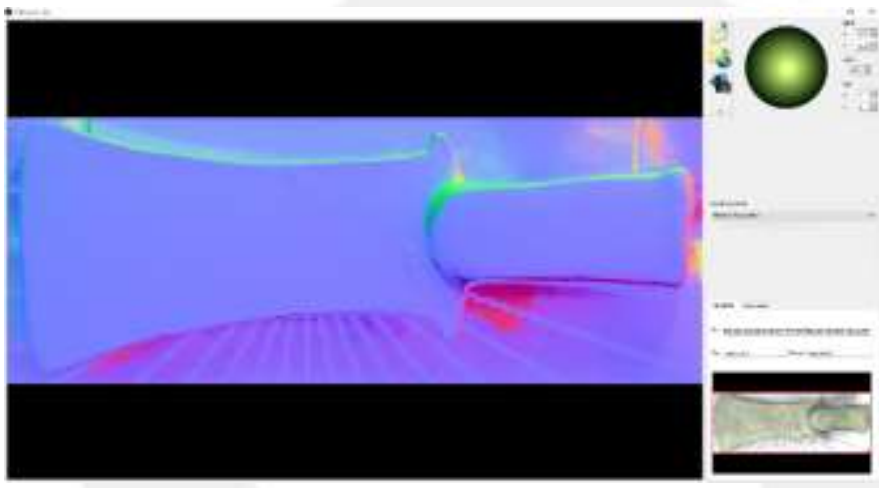

Fig 12

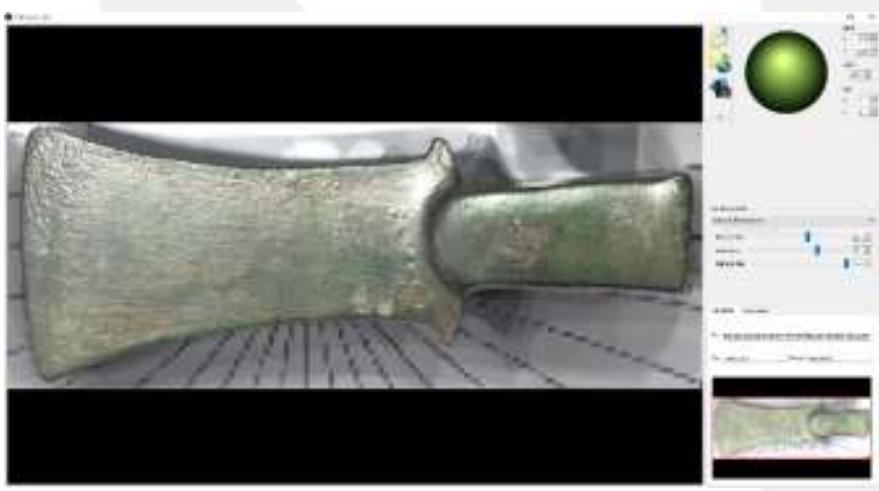

Fig. 13 
Figuras 11 a 13. Software RTI Viewer processando objeto machado de bronze.

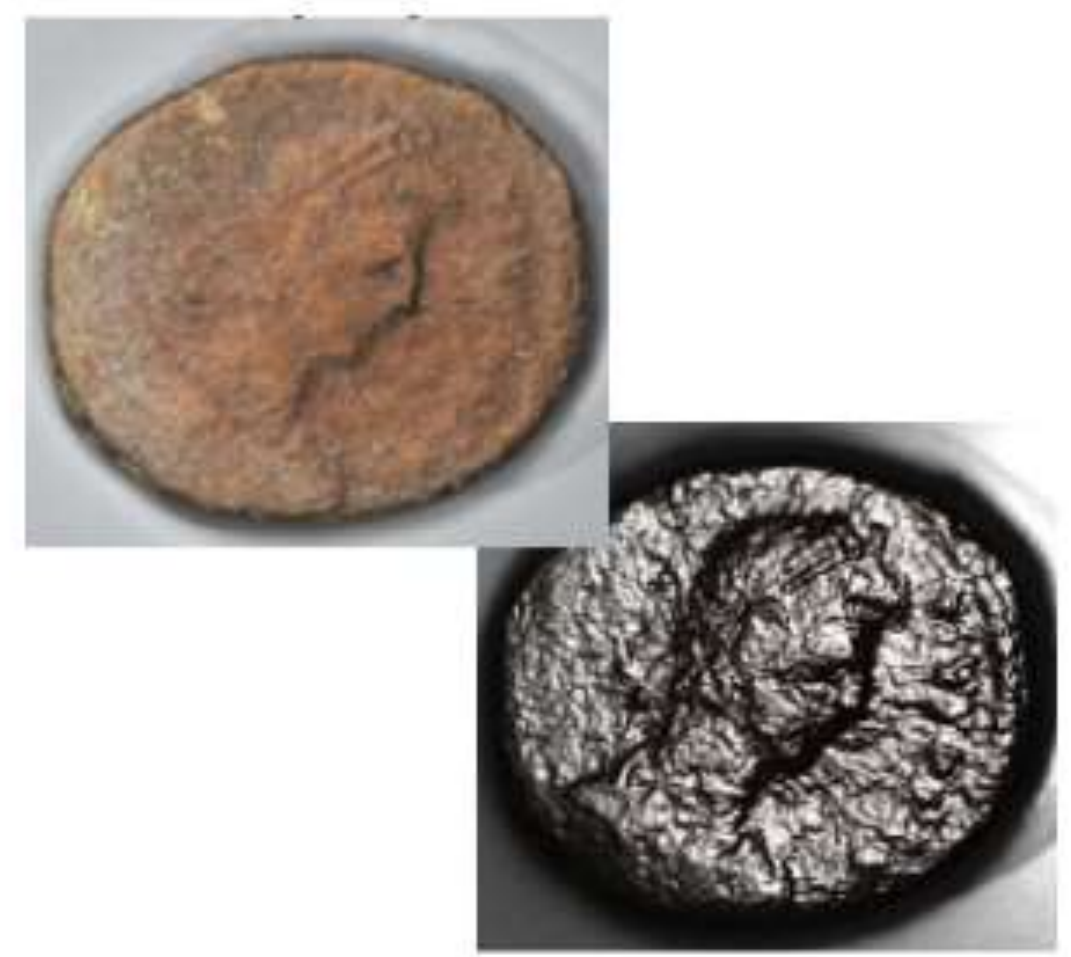

Antes e depois do processo de realce especular na moeda 64-48/MAE-USP.

Fig. 14 - Uso do RTI para detalhamento da decoração não nítida a olho nu. Aplicação RTI pela equipe de RTI - Projeto Acervos de Moeda MAE-USP, 2021

Os métodos de captura podem ser de duas formas, por meio de uma cúpula e de captura comum de fotografia, como podemos observar nos exemplos abaixo:
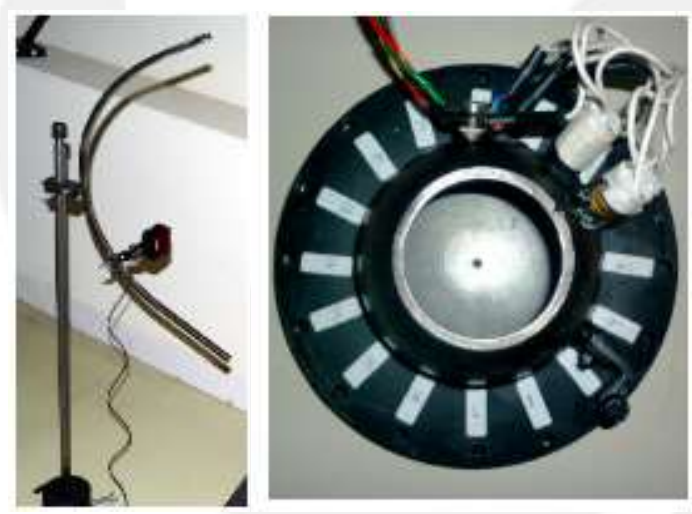

Fig. 15 - Exemplo de usos para captura RTI (esquerda captura mecânica e direita captura pelo mini domo) (Katoula; Kyranoudi, 2013, p.78). 


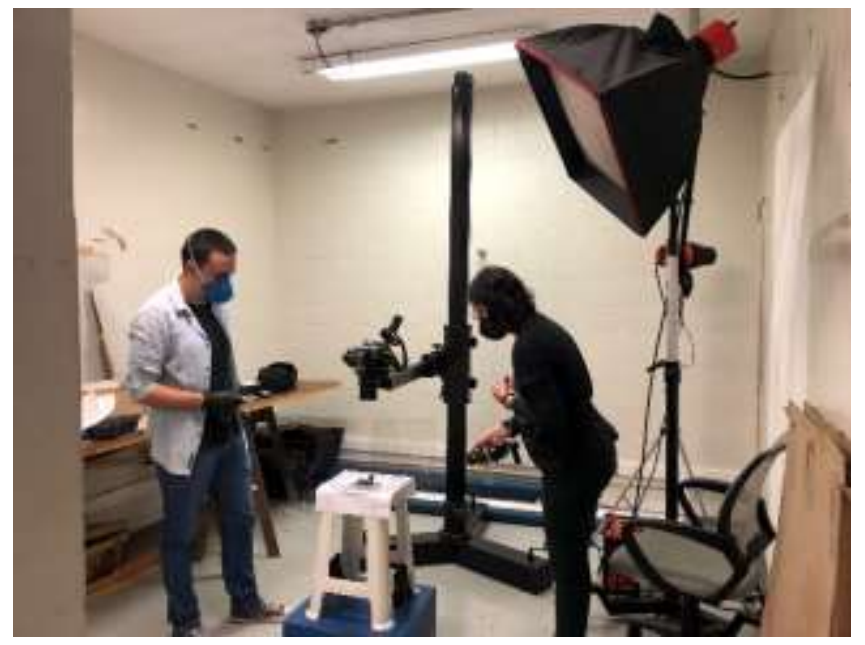

Fig.16. Trabalho da Equipe de RTI Jéssica Mendes e Guilherme Rodrigues

O nosso trabalho buscou a utilização da captura mecânica para a manipulação aplicada no software gratuito, acima mencionado, RTI Viewer, que nos permite estabelecer os jogos de sombra e luz, permitindo que os resultados fossem lançados e disponibilizados como link no Banco de Dados. Em nossa pesquisa, aplicamos a técnica em uma porcentagem amostral dos objetos do acervo, destacando, principalmente os que são passíveis de se detalhar marcas de uso e revelar possíveis técnicas que não podem ser vistas a olho nu. A aplicação da técnica permitiu-nos a visualização e maior acessibilidade do acervo, divulgação online, preservação do patrimônio, análise mais precisa dos artefatos assim como: geometria, técnica de confecção e alterações de uso do artefato. As soluções práticas da técnica aplicada aos metais de pequeno porte, permitiu-nos a reconstrução e conservação das peças, por meio da análise meso-escalar, reconstruindo visualmente o objeto a partir de efeitos de ilusão.

No Brasil, há um estudo desenvolvido pela pesquisadora Adriene Baron Tacla, da UFF - RJ intitulado “As moedas 'célticas' do Museu Histórico Nacional na fronteira digital”, em andamento. Esta pesquisa foi publicada no site da antiquitebnf.hypotheses.org. Este projeto, de acordo com a pesquisadora, considera a visualização digital, em particular as tecnologias 3D, com a finalidade de analisar, comparar e restaurar os objetos em metal, visando hipóteses de trabalho para a melhor compreensão dos achados arqueológicos, tanto do ponto de vista cognitivo (ou seja, da percepção) quanto de sua produção.

Neste sentido, a nossa preocupação com a conservação dos materiais levou-nos a pensar tanto no processo de detalhamento de técnicas para fins de aprofundamento dos estudos analíticos dos objetos de bronze e de ferro, como também na necessidade de conservação e restauração, pois o RTI possui a capacidade de trazer à luz elementos que nos permitem resgatar detalhes perdidos com o desgaste. No acervo de metais MMO do MAE-USP há peças em estado 
de conservação prejudicado, portanto técnicas e usos tecnológicos de enfoque de luz trabalhados em um software específico não invasivo, podem auxiliar nos processos de conservação e recuperação dos objetos, assim como compreender tecnicamente aspectos e correlações entre metalurgia e práticas rituais e/ou práticas funerárias, por meio de pormenores não visíveis a olho nu, como os objetos encontrados em contexto funerário, mencionados acima.

O RTI é uma ferramenta importante para revelar minuciosos detalhes de uso não perceptíveis, de compreensão de técnicas no metal, padrões de uso para estas regiões da Itália Meridional e Central. Permite, por sua vez, observar as mudanças feitas nos objetos ao longo do tempo, sendo de grande utilidade para compreender processos de destruição de decoração, inscrições e marcas de processo de produção, e de acordo com Adriene Tacla ${ }^{9}$, é uma maneira de recuperar a biografia dos objetos.

\section{Referências bibliográficas}

BARTOLONI Gilda; DELPINO Filippo. Oriente e Occidente: metodi e discipline a confronto. Riflessioni sulla cronologia dell'età del ferro in Italia. Pisa-Roma: Istituti Editoriali e Poligrafici Internazionali, 2005.

FARIELlO, Maria. Museo Archeologico Nazionale del Sannio Caudino, Castello Medievale, Montesarchio. Ministero per i Beni e le Attività Culturali. Soprintendenza per i Beni Archeologici delle province di Salerno, Avellino e Benevento, Italia. Roma: De Angelis Editore, 2007.

FLEMING, Maria Isabel D. A cultura romana e os povos do norte europeu. ln: Clássica. Suplemento, 2, 1993, p. 251-259.

FLEMING, Maria Isabel D. Contatos culturais na Península Itálica: as estatuetas de bronze. In: UFOP - LPH: Revista de História, Vol.5, p. 13-32, 1995.

FLEMING, Maria Isabel D. O Progresso na tecnologia do metal e inovações cerâmicas no mundo greco-romano. In: Revista do Museu de Arqueologia e Etnologia, São Paulo, Suplemento 2, p. 41-47, 1997.

FLEMING, Maria Isabel D. O trabalho do metal no contexto do Mediterrâneo arcaico. In: Resumos do XVI Congresso Nacional de Estudos Clássicos "Ócio \& trabalho no mundo antigo", 3 a 7 de setembro de 2007. Araraquara, São Paulo, 2007, p. 50-51.

FLEMING, Maria Isabel; FLORENZANO, Maria Beatriz B. Trajetória e perspectivas do Museu de Arqueologia e Etnologia da USP (1964-2011). Estudos Avançados, v. 25, p. 217 228, 2011.

GUERRA, Amílcar. Contextos histórico-culturais que enquadram a fundação de Roma. In: OLIVEIRA, Francisco; BRANDÃO, José Luís (coord.). História de Roma Ântiga, vol. I: das origens à morte de César. Coimbra: Imprensa da Universidade de Coimbra/Coimbra University Press, 2015, p. 13-16.

HOLLOWAY, Ross R. The archaeology of early Rome and Latium. London \& New York: Routledge, 1994.

\footnotetext{
${ }^{9}$ https://antiquitebnf.hypotheses.org/1746, consultado em 17/05/2018.
} 
KOTOULA, Eleni; KYRANOUDI, Maria. Study of ancient Greek and Roman coins using reflectance transformation imaging. E-conservation Magazine, v. 25, p. 74-88, 2013.

NIJBOER, Albert J. Italy, its Interconnections and Cultural Shifts During the Iron Age. Bolletino di Archeologia on-line, I 2010/Volume speciale F/F2/1, p. 2-22, 2010. Disponível em: https://bollettinodiarcheologiaonline.beniculturali.it/wpcontent/uploads/2020/10/1_NIJBOER.pdf. Acesso em: 30/11/2021.

OLIVER, Andrew. Greek, Roman, and Etruscan Jewelry. The Metropolitan Museum of Art Bulletin, v. 24, n. 9, p. 269-284, 1966.

ROMITO, M. Vecchi scavi, nuovi studi. Museo Archeologico Provinciale della Lucania Occidentale nella Certos di San Lorenzo a Padula, 2006. Italia dei Sanniti. Guida alla mostra, Roma, 2000.

SHEFTON B. B. Contacts between Picenum and the Greek world to the end of the fifth century B.C. Imports, influences and perceptions. In: I Piceni e l'Italia medio-adriatica. Atti del XXII Convegno di studi etruschi ed italici (Ascoli Piceno, Teramo Ancona, 9-13 aprile 2000). Roma, 2003, p. 315-337.

SUANO, Marlene; SCOPACASA, Rafael. Central Apennine Italy: The case of Samnium. In: DE ROSE EVANS, Jane (org.). A companion to the archaeology of the Roman Republic. Oxford: Blackwell Publishing Ltd., 2013, p. 387-405.

VAN DOMMELEN, Peter. Postcolonial Archaeologies between Discourse and Practice. World Archaeology, v. 43, n. 1, p. 1-6, 2011.

VAN DOMMELEN, Peter. Colonial matters. Material culture and Postcolonial theory in colonial situations. In: TILLEY, Chris; KEANE, Webb; KUECHLER, Susan; ROWLANDS, Mike; SPYER, Patricia (Org.). Handbook of Material Culture. London: Sage, 2006, p. 104124. 